\title{
Cultural Aesthetic Comparison of "Three Singing Methods"
}

\author{
Xiaolan Xie \\ College of Music, Hengyang Normal University, Hengyang, 421002, China
}

\begin{abstract}
The art of music is an important part of human culture. Vocal music art is closely related to traditional culture. Different social, historical and cultural factors of different nationalities have injected different ideological and cultural connotations into vocal music art. In their respective cultural atmosphere, vocal music art presents very different forms of expression. The traditional cultural concepts and national psychological consciousness formed under different religious backgrounds affect the traditional artistic concepts and the trend of vocal music art, and finally lead to the differences between Chinese and Western vocal music art and cultural aesthetics.
\end{abstract}

Keywords: "Three Singing Methods", Comparison, Cultural aesthetic.

\section{Introduction}

In a broad sense, aesthetic consciousness should "include all aspects of aesthetic consciousness activities and various forms of expression, such as aesthetic taste, aesthetic ability, aesthetic idea, aesthetic ideal, aesthetic feeling and so on." The aesthetic consciousness of artistic singing mainly refers to the aesthetic feeling, that is, a special psychological phenomenon in the artistic creation and appreciation activities of the singer, aesthetic feeling. It is based on personal hobbies and interests as the starting point, affected and restricted by the social background, cultural upbringing, personal experience, personality characteristics of the individual, thus forming personal hobbies and tastes in singing vary in thousands of ways, which also forms the diversity of aesthetic feeling.

\section{The Differences in Cultural Connotation of "Three Singing Methods"}

\subsection{From A Philosophical Point of View}

European culture pays more attention to rational analysis, pays more attention to the split between reason and sensibility, essence and phenomenon. Under the influence of Confucian culture for thousands of years, Chinese culture emphasizes harmony, attaches importance to the unity of reason and sensibility, and the unity of essence and phenomenon. Integration is not only the symbol of Chinese culture, but also the symbol of Chinese traditional vocal music art and cultural spirit. Split is not only the characteristic of European culture, but also the cultural characteristic of western traditional vocal music art.

Westerners are good at philosophical thinking about the past and the future with rational thinking. The birth of opera is the direct reason for the formal formation of "bel canto singing" and promotes the "bel canto singing" with the development of opera art and gradually mature. Therefore, the humanism trend of the Renaissance movement and the rise of grand opera are the exact basis for the emergence of bel canto and the formation of numerous schools in the later development. Therefore, the school of bel canto singing is first of all the school of literary and artistic thought. In the process of its development, not only bishops, composers and music theorists made great contributions to vocal music art, but even doctors and scientists also participated in the process and promoted the transformation of vocal music practice and artistic theory. In modern times, due to the rapid development of modern science and technology, the vocal music theory of bel canto school was combined with natural science earlier, thus forming the scientific theoretical system of voice singing Bel canto school vocal music theory into the physiology, psychology, physics, acoustics, medicine and other related disciplines of scientific theory research results, further systematically study the rule of the nature of the singing voice, set up scientific singing training system, makes the "bel canto" singing model of perfect combination of art and science. In terms of artistic creation, due to the mature system of notation and renaming, the composer has a higher social status, so its vocal music art is more logical and systematic, aesthetic standards tend to be realistic, and it pays attention to the narrative and philosophy of singing content in the form of vocal music expression. It can be said that Belcant not only represents a singing style, but also represents certain aesthetic principles and artistic thoughts and schools. It is because of the Bel Canto which is a collection of a variety of disciplines and the diversity of the existence of the system and integrity of the vocal music education system, the western vocal music culture in the modern mainstream status.

\subsection{The Traditional Music Culture in Our Country}

The traditional music culture in our country mainly consists of four parts, namely, palace music, literati music, religious music and folk music, and the national vocal music is mainly developed on the basis of folk music generated, absorbing the Chinese opera, rap music art essence of traditional folk art, such as in this sense folk singing is the continuation and development of Chinese traditional music culture. At the same time, China has a vast territory and has been a multiethnic country since ancient times. In Chinese history, China has experienced several major ethnic integration. With its broad mind, Chinese national vocal music art absorbs the musical culture of various regions and nationalities, making it a vocal music art generated by the fusion and intersection of the singing art of Han ethnic music and other ethnic music. 
This kind of regional culture and national culture make the national singing style present diversified characteristics of various singing styles and forms of expression.

The main line of the evolution and development of our national singing method is the Han folk song and dance. The formation of Han nationality's musical aesthetics is based on the thought of "perfection" and "perfection" proposed by Confucius in the Spring and Autumn Period and the Warring States Period. It distinguishes the beauty of content and form for the first time in aesthetics, and regards the unification of the two as the symbol of the highest state of beauty. Harmony is a very prominent feature in ancient Chinese aesthetic thought. "Harmony" is the aesthetic concept of moderation. Harmony means to seek balance and unity in the contradiction and opposition of things. As an important value standard, "harmony" has been running through the music culture of the Han nationality for more than two thousand years. Under the artistic and cultural influence of the Confucian thought of "harmony", Chinese national vocal music pursues the harmony and unity of word and sound, emotion and word, art and technology in the aesthetic tradition, pays attention to the implicit, the mean, pays attention to the group's identity, pays attention to the harmonious "beauty of harmony". However, this kind of attitude that emphasizes the inner introspection and the mean lacks the individualism spirit and individual needs of western culture, and lacks the in-depth rational analysis and speculation of western people.

If the national singing method is based on the cultural tradition of the Chinese nation and the bel canto method is based on the cultural tradition of Europe, then the popular singing method does not reflect the rich and diverse historical and cultural connotation. It is a popular and fashionable mass entertainment culture. As the carrier of "popular singing", pop songs originated from the black music culture in Africa and developed in Latin America and other countries in modern times. Many aspects of popular music have been influenced by Latin American folk music. As a kind of popular culture, pop music on the one hand has the characteristics of popularity, entertainment and commercial; On the other hand, it reflects the life thought, spiritual demand and social content of modern people who take urban life as the main body, which is quite universal, rapid and profound. In the late 1980s and early 1990s, the famous Taiwanese musician Luo Dayou's "Childhood", "Love in 1990", "Tomorrow will be better" and other works with beautiful melodies and lyrics full of humanistic care and ideological depth are still regarded as the classics of pop music because they reflect the author's deep concern for society, life and values.

\section{The Essence of Cultural Connotation of "Three Singing Methods"}

To sum up, the three singing styles actually represent three cultures and characteristics. Different forms of art exist due to their different historical origins and cultural backgrounds. However, because the "three singing methods" belong to the same cultural art -- vocal art, they still have many similarities in cultural essence:

\subsection{The Reflection of Human Nature}

no matter what theme or content is reflected in the vocal music works are the art of expressing people's thoughts and feelings, are the reflection of human nature in the display of human nature.
From the perspective of historical development, the prosperity and prosperity of western opera art and Chinese opera art signified that both Chinese and western vocal music art gradually got rid of the bondage of the court or the church and became the art of the public, and thus jointly embarked on the peak of development. The birth of opera benefited from the Renaissance movement and humanism thought. Although church music influenced bel canto singing to a large extent, the rise of secular operas such as comic opera pulled bel canto back from the asceticism of expressing and praising God to the humanism of advocating human beings, expressing the joys, anger, sorrow and music of life, and eulogizing and praising life. Since the An-Shi Rebellion of the Tang Dynasty, many court artists have been lost to the people. At the same time, since the Song Dynasty, the rise of cities enabled civic music to flourish. The folk vocal music has changed from the court song and dance to the drama reflecting the secular life. Guan Hanqing, a famous playwright in the Yuan Dynasty, played an important role in the development of opera in the future, which took the sufferings of common people, especially young women as the background. Pop music itself is a culture created by the masses for themselves. "Popular" means to be popular with the audience, which is more close to life, directly meets the physical and psychological needs of the urban public, and quietly shapes the public's interests and ideas in their daily life.

\subsection{The Artistic Expression of "Three Singing Methods"}

The artistic expression of "three singing methods"is the close combination of vocal music art and literary art. The foundation of vocal music art is the combination of music and literature, and the poetic and musical artistic language is the literary foundation of the artistic beauty of the song. The change of ancient Chinese vocal music art form and the progress of singing art have always been closely related to the change and development of literature and art. From "The Book of Songs", the earliest collection of poems in China, to the later poems of Chu and Yuefu, to the poems of Tang, Song and Yuan, these classic arts are all the products of the combination of literature and vocal music. The ancient Chinese artists have long noticed the relationship between the language sound and singing. They recited the poems with the changes of rhyme and sound, which constituted the artistic style and singing technology system which mainly focused on chanting. Similarly, many works of bel canto emphasize the artistic combination of music and poetry.

The different cultural background and thinking mode of vocal music lead to the different traditional aesthetic thoughts of vocal music, which is not only reflected in the creation, but also in the aesthetic judgment of sound, the most essential carrier of vocal music art, which is concentrated in the different aesthetic requirements of "three kinds of singing methods" in timbre, quality and volume.

\subsection{Differences in Emotional Aesthetics}

Both bel canto and national singing are relatively implicit in the expression of emotions, while popular singing is more direct in the expression of emotions, without too much decoration. Pop songs directly reflect the spiritual needs of people of different social strata, and at the same time have the characteristics of popularity and popularity. Therefore, in terms of emotional expression, they pay more attention to the enhancement and externalization of emotions, so that the 
audience, regardless of the level of education and artistic accomplishment, can get a direct resonance through the singer's singing. The simplicity of pop tunes, the simplicity of lyrics, and the freedom and diversity of singing techniques and styles are closely related to this. This direct expression can be said to be a natural and natural emotional outpouring. Whether expressing family affection, friendship and love, or local affection, they are closely related to one's personal feelings. For example, campus folk songs are popular on campus mainly because students share the same experience and feelings with the singers.

\section{Conclusion}

Western art song creation is based on selection of famous poet in the poetry of pure literature, and the composer's mission is to make their music and poetry connotation is consistent, from the weight of the each word syllable to logical stress, and other details that every sentence lyrics and music to cooperate, nuanced to express the image of poetry, poetry emotion, the artistic conception of poetry. The lyrics of popular songs are often regarded as unserious and difficult to take seriously. This is actually a prejudice. The lyrics of many popular songs are also of high artistic quality. Such as "curved moon" lyrics: "the distant night sky, there is a curved moon, curved moon below, is that curved small bridge. There is a small bridge next to a curved boat, curved boat long, is the childhood of Gillian......"; The lyrics of this song can be said to be a work of high literary grade, with poetic language, colloquial expression has become a classic pop song.

\section{References}

[1] Hu Qinsheng. Comparison between the characteristics of opera and art songs [J]. Journal of Anshan Normal University, 2010 (02).

[2] Wang Li. The singing style of Chinese national vocal music [J]. Journal of West Anhui University, 2003 (04).

[3] Lin Xiaobo. Shape language and design in vocal music singing [J]. Theory and Creation, 2009 (04).

[4] The high moon glow. The role of body language in song singing [J]. The Voice of Yellow River, 2009 (02).

[5] Shen Ping. Reflections on Vocal Performance of Songs [J]. Popular Art, 2012 (11). 